\title{
Analisis Kualitas Air Sumur Gali Ditinjau Dari Parameter Kimia (Cl Dan Fe) Di Kelurahan Mangempang Kecamatan Barru Kabupaten Barru
}

\author{
${ }^{1}$ Andi Rizky Amaliah \\ ${ }^{2}$ Ardianti \\ ${ }^{1}$ Sekolah Tinggi Ilmu Kesehatan Makassar, Indonesia \\ ${ }^{2}$ Sekolah Tinggi Ilmu Kesehatan Makassar, Indonesia
}

Alamat Korespondensi:

Nama Koresponden : Andi Rizky Amaliah

Bagian : Ilmu Kesehatan Masyarakat

Institusi penulis : Sekolah Tinggi Ilmu Kesehatan Makassar

No.Hp / telfn : :085329999299

Email penulis : :qkyrizkyamaliah@yahoo.com 


\begin{abstract}
ABSTRAK
Air sangat dibutuhkan oleh makhluk hidup khususnya sebagai air minum, namun air juga menimbulkan berbagai gangguan kesehatan misalnya diare. Tujuan penelitian ini untuk mengetahui kualitas air sumur gali ditinjau dari parameter kimia ( $\mathrm{Cl}$ dan $\mathrm{Fe}$ ) di Kelurahan Mangempang Kecamatan Barru Kabupaten Barru. Jenis penelitian yang digunakan adalah penelitian survey dengan pendekatan deskriptif. Sampel dalam penelitian ini adalah air sumur gali sebanyak 12 yang berada di Kelurahan Mangempang Kecamatan Barru Kabupaten Barru kemudian dilakukan pemeriksaan laboratorium. Hasil penelitian menunjukkan bahwa kualitas sumur gali parameter kimia $\mathrm{Cl}$ di Kelurahan Mangempang Kecamatan Barru Kabupaten Barru dari 12 sumur gali yang diteliti ternyata 4 sumur gali tidak memenuhi syarat kesehatan yaitu $\leq 600 \mathrm{mg} / \mathrm{l}$. sedangkan kualitas sumur gali parameter kimia Fe di Kelurahan Mangempang Kecamatan Barru Kabupaten Barru dari 12 sumur gali yang diteliti ternyata 2 sumur gali tidak memenuhi syarat kesehatan yaitu $\leq 1,0 \mathrm{mg} / \mathrm{l}$. Simpulan yang diperoleh dalam penelitian ini bahwa kualitas air sumur gali berdasarkan parameter kimia $\mathrm{Cl}, 4$ dari 12 sumur gali yang diperiksa tidak memenuhi syarat kesehatan dan Kualitas air sumur gali berdasarkan parameter kimia Fe, 2 dari 12 sumur gali yang diperiksa tidak memenuhi syarat kesehatan. Disarankan bagi petugas kesehatan setempat agar kiranya bisa turun memeriksa sumur-sumur gali masyarakat.
\end{abstract}

Kata Kunci : Kualitas air, Sumur Gali, Cl, Fe

\begin{abstract}
Water is needed by living things especially as drinking water, but water also causes various health problems such as diarrhea. The purpose of this study was to determine the quality of dug well water in terms of chemical parameters ( $\mathrm{Cl}$ and $\mathrm{Fe}$ ) in Mangempang Village, Barru District, Barru Regency. This type of research is survey research with a descriptive approach. The sample in this study was 12 dug well water in Mangempang SubDistrict, Barru Sub-District, Barru District, and then conducted a laboratory examination. The results showed that the quality of $\mathrm{Cl}$ chemical wells dug Cl in Mangempang Village Barru District Barru Regency of the 12 dug wells studied turned out to be 4 dug wells not meeting health requirements that are $\leq 600 \mathrm{mg} / \mathrm{l}$. while the quality of the dug wells chemical parameters Fe in Mangempang Village Barru District Barru Regency of the 12 dug wells studied turned out to be 2 dug wells not meeting health requirements that are $\leq 1.0 \mathrm{mg} / \mathrm{l}$. Conclusions obtained in this study that the quality of dug well water based on chemical parameters $\mathrm{Cl}, 4$ of the 12 dug wells examined did not meet health requirements and the dug well water quality based on chemical parameters Fe, 2 of the 12 dug wells examined did not meet health requirements. It is recommended for local health workers to be able to go down to inspect community dug wells.
\end{abstract}

Keywords : Water quality, well water, $\mathrm{Cl}, \mathrm{Fe}$ 


\section{PENDAHULUAN}

Air adalah materi esensial di dalam kehidupan. Air sangat dibutuhkan oleh makhluk hidup khususnya sebagai air minum, namun air juga menimbulkan berbagai gangguan kesehatan terhadap si pemakai khususnya diare. Oleh karena itu, air harus bebas dari pencemaran dan memenuhi tingkat kualitas tertentu sesuai dengan kebutuhan kadar di dalam tubuh manusia (Rini Novita Sunarti, 2015). Air dapat menjadi sumber bencana apabila tidak tersedia sebagaimana peruntukannya. Secara kuantitas, distribusi airtanah di muka bumi tidak merata dan bervariasi menurut ruang dan waktu, sedangkan secara kualitas, air tanah mengandung senyawa kimia dan organik baik dalam skala kecil bahkan berlebihan dan mudah terkontaminasi oleh bahan pencemar (E. R. Tuwu dan S.C.R. Kete, 2017).

Sanitasi dan perilaku kebersihan yang buruk serta air minum yang tidak aman berkontribusi terhadap 88 persen kematian anak akibat diare di seluruh dunia. Bagi anak-anak yang bertahan hidup, seringnya menderita diare berkontribusi terhadap masalah gizi, sehingga menghalangi anak-anak untuk dapat mencapai potensi maksimal mereka. Kondisi ini selanjutnya menimbulkan implikasi serius terhadap kualitas sumber daya manusia dan kemampuan produktif suatu bangsa di masa yang akan datang. Di Indonesia, diare masih merupakan penyebab utama kematian anak berusia di bawah lima tahun. Laporan Riskesdas menunjukkan diare sebagai penyebab $31 \%$ kematian anak usia antara 1 bulan hingga satu tahun, dan $25 \%$ kematian anak usia antara satu sampai empat tahun. Angka diare pada anak-anak dari rumah tangga yang menggunakan sumur terbuka untuk air minum tercatat $34 \%$ lebih tinggi dibandingkan dengan anak-anak dari rumah tangga yang menggunakan air ledeng (Unicef Indonesia, 2012).

Data dari WHO (Wordl Health Organisation) tahun 2013 menunjukkan angka kematian sekitar 10 juta penduduk setiap tahun oleh berbagai penyakit yang berkaitan dengan pencemaran air. Diare merupakan penyakit yang paling sering terjadi akibat pencemaran air. Angka kejadian diare pada tahun 2013 yaitu sebesar 3,5\% dan khusus di Sulawesi Selatan yaitu 5,2\% (Riskesdas, 2013).

Berdasarkan profil kesehatan provinsi Sulawesi Selatan pada tahun 2016 menunjukkan persentase keluarga menurut jenis sarana air bersih yang digunakan untuk keperluan rumah tangga dan untuk keperluan air minum. Secara nasional, persentase tertinggi jenis sarana air bersih yang digunakan untuk keperluan rumah tangga adalah air sumur gali terlindung 
(27,9\%), sumur bor/pompa (22,2\%), dan air ledeng/PAM (19.5\%). Sedangkan persentase tertinggi jenis sarana air bersih yang digunakan untuk air minum adalah sumur gali terlindungi $(24,7 \%)$, air ledeng/PAM (14,2\%) dan sumur bor/pompa (14\%) (Profil Kesehatan Prov Sulawesi selatan, 2016).

Akses air minum pada tahun 2014 menurut data dari bidang P2PL (Pengendalian Penyakit dan Penyehatan Lingkungan) sebesar 70,37\% dibanding tahun 2013 terjadi peningkatan capaian dari sebesar $68,8 \%$ dan mengalami penurunan jika dibandingkan pada tahun 2012 yaitu sebesar $89.2 \%$. Persentase tertinggi adalah dengan menggunakan sumur gali terlindung sebesar 21,2\% (Profil Kesehatan Kabupaten Barru 2014). Tujuan dari penelitian ini adalah Untuk mengetahui kualitas air sumur gali Kelurahan Mangempang ditinjau dari parameter klorida $(\mathrm{Cl})$ dan ditinjau dari parameter $(\mathrm{Fe})$.

\section{METODE}

Jenis penelitian ini adalah penelitian survei dengan pendekatan deskriptif. Penelitian dilakukan di Lingkungan Abbatunge Kelurahan Mangempang Kecamatan Barru Kabupaten Barru bulan Juni tahun 2018 dan uji parameter dilakukan di Laboratorium Kesehatan Makassar Jurusan Kesehatan Lingkungan.
Yang menjadi populasi dalam penelitian ini adalah semua sumur gali yang ada di Kelurahan Mangempang Kecamatan Barru Kabupaten Barru dengan jumlah sumur yang beresiko (sumur terbuka) sebanyak 116 unit.

Sampel dalam penelitian ini adalah $10 \%$ dari seluruh sumur gali yang beresiko yaitu 116 di Kelurahan Mangempang Kecamatan Barru Kabupaten Barru yaitu sebanyak 12 sumur gali. Jika subjeknya kurang dari 100 sebaiknya diambil semuanya, jika subjeknya besar atau lebih dari 100 dapat diambil $10-15 \%$ atau 2025\% atau lebih (Suharsimi Arikunto, 2010). Metode penarikan sampel dilakukan secara Purpossive sampling yaitu dengan didasarkan pada suatu pertimbangan dan kriteria tertentu yang dibuat oleh peneliti sendiri.

\section{HASIL}

Pada Tabel 1 menunjukkan bahwa Air sumur yang dijadikan sampel diambil dari beberapa titik yang ada di Kelurahan Mangempang, dimana pada Kelurahan Mangempang terdapat 5 Lingkungan yaitu Lingkungan Mangempang terdapat 7 sumur gali. Lingkungan Abbatunge terdapat 26 sumur gali. Lingkungan Garongkong terdapat 10 sumur gali. Lingkungan Gempunge terdapat 46 sumur gali. Lingkungan Padongko terdapat 27 sumur gali. 
Pada tabel 2 menunjukkan bahwa kualitas sumur gali parameter kimia klorida $(\mathrm{Cl})$ di Kelurahan Mangempang Kecamatan Barru Kabupaten Barru dari 12 sumur gali yang diteliti ternyata hasilnya 8 sumur gali memenuhi syarat kesehatan dan 4 sumur gali tidak memenuhi syarat kesehatan.

Pada tabel 3 menunjukkan bahwa kualitas sumur gali parameter kimia besi (Fe) di Kelurahan Mangempang Kecamatan Barru Kabupaten Barru dari 12 sumur gali yang diteliti ternyata hasilnya 10 sumur gali memenuhi syarat kesehatan dan 2 sumur gali tidak memenuhi syarat kesehatan.

\section{PEMBAHASAN}

Standar mutu air minum atau air untuk kebutuhan rumah tangga ditetapkan berdasarkan Peraturan Menteri Kesehatan Republik Indonesia No. 492/Menkes/ Per/IV/2010 tentang Persyaratan Kualitas Air Minum. Sedangkan standar baku mutu air bersih ditetapkan berdasarkan Permenkes

No.416/MENKES/PER/IX/1990 tentang Persyaratan Kualitas Air Bersih.

\section{a. Klorida $(\mathrm{Cl})$}

Berdasarkan hasil pemeriksaan laboratorium menunjukkan bahwa dari 12 sumur gali terdapat 4 sumur yang memiliki kadar klorida $(\mathrm{Cl})$ dalam air tidak memenuhi syarat sesuai berdasarkan
Permenkes

No.416/MENKES/PER/IX/1990 tentang Persyaratan Kualitas Air Bersih yaitu $\leq$ $600 \mathrm{mg} / \mathrm{l}$.

Klorida adalah ion yang terbentuk dari unsur klor yang mendapatkan satu elektron untuk membentuk suatu anion atau ion yang bermuatan negative ( $\mathrm{Cl}-$ ). Kata klorida dapat pula diartikan sebagai senyawa kimia dimana satu atau lebih atom klornya memiliki ikatan kovalen dalam molekul. Tingkat toksisitas klorida tergantung pada gugus senyawanya, misalnya Natrium Klorida $(\mathrm{NaCl})$ sangat tidak beracun, tetapi karbonil khlorida sangat beracun.

Beberapa dampak yang ditimbulkan oleh klorida pada lingkungan adalah menimbulkan pengkaratan atau dekomposisi pada logam karena sifatnya yang korosif, ikan dan biota air tidak bisa bertahan hidup dalam kadar klorida yang tinggi serta kerusakan ekosistem pada perairan terbuka atau eutrofikasi.

Hasil penelitian yang dilakukan oleh Endar Budi Sasongko, Endang Widyastuti dan Rawuh Edy Priyono (2014) kandungan klorida di Sungai Kaliyasa sangat tinggi yaitu 17.088,55 mg/l, tidak memenuhi baku mutu air bersih $(600 \mathrm{mg} / \mathrm{l})$. Tingginya klorida di Sungai Kaliyasa selain didapat dari air laut yang mengandung garam, juga dari limbah rumah tangga yang dibuang ke 
Sungai Kaliyasa. Kotoran manusia, khususnya urin mengandung klorida dalam jumlah yang sama dengan klorida yang dikonsumsi lewat makanan dan air.

Hasil penelitian yang dilakukan oleh Siti Munfiah, Nurjazuli, Onny Setiani (2013) di wilayah kerja Puskesmas Guntur II menunjukkan kadar klorida $(\mathrm{Cl})$ air sumur gali 57,11-2884,57 mg/l. Kadar klorida (Cl) air sumur bor 22,72-158,08 mg/l. Batas maksimum klorida dalam sumber air bersih adalah $600 \mathrm{mg} / \mathrm{l}$ dan air minum $250 \mathrm{mg} /$ 1. Hasil penelitian diperoleh sumur gali dengan kadar klorida melebihi baku mutu air bersih sebanyak 4 sumur (20\%) dan 9 sumur gali (45\%) dengan kadar klorida yang melebihi baku mutu air minum. Semua sumur bor (100\%) dengan kadar klorida yang memenuhi syarat air bersih dan air minum.

Sumber klorida dalam air permukaan dan air tanah dapat terjadi secara alami dan akibat kegiatan manusia seperti air limpasan, penggunaan pupuk anorganik, air lindi dari persampahan, limbah septic tank, pakan ternak, limbah industri, saluran drainase atau irigasi, dan intrusi air laut di wilayah pesisir. Konsentrasi klorida 250 $\mathrm{mg} / \mathrm{l}$ merupakan batas maksimal konsentrasi yang dapat menimbulkan rasa asin.

Hasil penelitian yang dilakukan oleh Tri Puji Kurniawan (2015) menunjukkan bahwa kadar klorida $(\mathrm{Cl})$ air sumur artesis ada di antara 43,01 - 52,45 mg/l. Batas maksimum klorida sebagai sumber air bersih adalah $600 \mathrm{mg} / \mathrm{l}$ dan sebagai air minum $250 \mathrm{mg} / \mathrm{l}$. Hasil penelitian diperoleh hasil bahwa seluruh sumur artesis memiliki kadar klorida di bawah baku mutu air bersih dan air minum, yang berarti memenuhi syarat. Hasil survey pendahuluan yang dilakukan pada tanggal 18 Januari 2015 Di Perum Pondok Baru Permai di Bulak Rejo, Sukoharjo, menemukan bahwa kualitasair di sana buruk. Jika dilihat dari segi fisik, air berbau amis, keruh, menimbulkan warna kuning dan coklat pada air dan dinding kamar mandi. Hal tersebut mengindikasikan kandungan Fe dalam air yang melebihi baku mutu air minum.

Pada survey tersebut dilakukan pemeriksaan terhadap beberapa parameter fisik dan kimia pada air yang bersumber pada air tanah yang dapat berpengaruh terhadap kesehatan manusia. Parameter fisik kualitas air tersebut meliputi warna dan total dissolved solids (TDS) sementara parameter kimianya meliputi: besi, kesadahan total, klorida, mangan, nitrat sebagai $\mathrm{N}$, nitrit sebagai $\mathrm{N}, \mathrm{pH}$, sulfat dan zat organik.

Berdasarkan penelitian yang dilakukan oleh Tuwu E, R dan Kete, S, C,R (2017) mengatakan bahwa khlorida 
memiliki kadar dalam air relative tetap. Ion khlorida dalam air akan meningkat apabila kandungan mineral meningkat, karena dipengaruhi oleh jenis batuan. Selain itu, ion kholrida juga dapat bersumber dari urine manusai yaitu sekitar enam gram/hari/orang.

Hasil analisis laboratorium menunjukan bahwa kadar khlorida terrendah yaitu pada titik sampel 3 sebesar 24,16 mg/l dan tertinggi sebesar 101,2 $\mathrm{mg} / \mathrm{l}$ pada sampel 6. Sampel 6 tersebut diambil dari rumah penduduk yang padat dengan kontruksi sumur yang kurang baik karena tidak memiliki lantai sumur yang kedapa air. Kondisi ini diperparah dengan topografi agak landai dan tidak mempunyai saluran drainase sehingga limbah rumah tangga dibuang begitu saja dan letak kamar mandi dengan sumur sangat dekat sehingga air sumur gali tersebut rentan terkontaminasi oleh bahan pencemar yang bersumber dari aktivitas penduduk sekitar.

Berdasarkan Peraturan Menteri Kesehatan No. 492/Menkes/Per/IV/2010 baku mutu yang diperbolehkan tidak lebih dari $250 \mathrm{mg} / \mathrm{l}$. Hal ini dapat disimpulkan bahwa meskipun terdapat beberapa sumur gali yang memiliki kontruksi sumur kurang baik dan berdekatan dengan saluran drainase, namun masih tergolong baik karena tidak melebih ambang batas yang telah ditentukan.
Hasil penelitian Tri Puji Kurniawan (2015) tentang Kualitas Kimia Air Sumur di Perum Pondok Baru Permai Desa Bulak Rejo Kecamatan Sukoharjo Kabupaten Sukoharjo menunjukkan kadar klorida $(\mathrm{Cl})$ air sumur artesis ada di antara 43,01 $52,45 \mathrm{mg} / \mathrm{l}$. Batas maksimum klorida sebagai sumber air bersih adalah $600 \mathrm{mg} / \mathrm{l}$ dan sebagai air minum $250 \mathrm{mg} / \mathrm{l}$. Hasil penelitian diperoleh hasil bahwa seluruh sumur artesis memiliki kadar klorida di bawah baku mutu air bersih dan air minum, yang berarti memenuhi syarat.

Hasil penelitian Nia Yuliani, Nurlela, Novia anggraeni Lestari (2017) tentang Kualitas Air Sumur Bor di Perumahan Bekas Persawahan Gunung Putri Jawa Barat menunjukkan bahwa kandungan klorida yang masih berada di bawah ambang batas maksimum yang diperbolehkan yaitu 0,5 hingga 1,8 mg/L. Kandungan klorida dari seluruh sampel cenderung sangat rendah, dan air sumur tidak mendapatkan kontaminasi yang berarti dari tanah, selokan, ataupun sungai di area perumahan. Sumber klorida dalam air permukaan dan air tanah dapat terjadi secara alami dan akibat kegiatan manusia seperti air limpasan, penggunaan pupuk anorganik, air lindi dari persampahan, limbah septic tank, pakan ternak, limbah industry, saluran drainase/irigasi dan intrusi air laut di wilayah pesisir. Standar 
parameter klorida berdasarkan Peraturan Menteri Kesehatan RI No. 416/MENKES/PER/IX/1990 maksimum yaitu $600 \mathrm{mg} / \mathrm{L}$.

\section{b. Besi (Fe)}

Berdasarkan hasil pemeriksaan laboratorium menunjukkan bahwa dari 12 sumur gali terdapat 2 sumur yang memiliki kadar besi $(\mathrm{Fe})$ dalam air tidak memenuhi syarat sesuai berdasarkan Permenkes RI No.416/MENKES/PER/IX/1990 tentang Persyaratan Kualitas Air Bersih yaitu $\leq 1,0$ $\mathrm{mg} / \mathrm{l}$.

Berdasarkan persyaratan kualitas air minum yang dibuat oleh Permenkes No.416/MENKES/PER/IX/1999, kadar besi maksimum yang diperbolehkan sebesar 1,0 mg/l. Besi dapat larut pada $\mathrm{pH}$ rendah dan dapat menyebabkan air yang berwarna kekuningan, menimbulkan noda pada pakaian dan tempat berkembang biaknya bakteri creonothrinx, oleh sebab itu kadar besi tidak boleh lebih dari 1 $\mathrm{mg} / \mathrm{L}$, karena dapat mempercepat pertumbuhan bakteri tersebut dan dapat menimbulkan rasa serta bau.

Kandungan besi dalam air juga diperlukan, tetapi kandungan besi yang terlalu tinggi dapat menganggu kesehatan. Besi di dalam air dapat menimbulkan bau, rasa, warna kuning, pengendapan pada dinding pipa, kekeruhan, merusak dinding usus, dan dapat menyebabkan kematian.
Kandungan zat besi yang melebihi $1 \mathrm{mg} / \mathrm{l}$ akan menyebabkan terjadinya iritasi pada mata dan kulit. Apabila kelarutan besi dalam air melebihi $10 \mathrm{mg} / \mathrm{l}$ akan menyebabkan air berbau seperti telur busuk.

Hasil penelitian yang dilakukan oleh Endar Budi Sasongko, Endang Widyastuti dan Rawuh Edy Priyono (2014) hasil pengukuran kandungan besi di Sungai Kaliyasa diketahui sebesar $2 \mathrm{mg} / \mathrm{l}$ melebihi baku mutu (1,0 mg/l), dan berakibat pada tingginya kandungan besi pada sumur terdekat. Hal ini dapat dilihat pada hasil pengukuran kandungan besi air sumur gali di sekitar Sungai Kaliyasa didapatkan air sumur gali yang mengandung besi paling tinggi adalah sumur gali yang jaraknya dekat dengan Sungai Kaliyasa kemudian menurun pada sumur gali yang jaraknya makin jauh dari sungai. Pengamatan satu dengan yang lain berdasar jarak sumur dengan sungai berbeda. Kelebihan zat Fe bisa menyebabkan keracunan, dimana terjadi muntah, diare, kerusakan usus, hemokromatosis, sirosis, kanker hati, diabetes, gagal jantung, artritis, impotensi, kemandulan, hopotiroid, dan kelelahan menahun.

Besi termasuk unsur yang penting bagi makhluk hidup. Pada tumbuhan, besi berperan sebagai penyusun sitokrom dan klorofil. Kadar besi yang berlebihan dapat 
menimbulkan warna merah, menimbulkan karat pada peralatan logam, serta dapat memudarkan bahan celupan (dyes) dan tekstil. Pada tumbuhan, besi berperan dalam sistem enzim dan transfer elektron pada proses fotosintesis. Besi banyak digunakan dalam kegiatan pertambangan, industri kimia, bahan celupan, tekstil, penyulingan, minyak, dan sebagainya. Pada air minum, Fe dapat menimbulkan rasa, warna (kuning), pengendapan pada dinding pipa, pertumbuhan bakteri besi, dan kekeruhan.

Besi dibutuhkan oleh tubuh dalam pembentukan haemoglobin. Banyaknya Fe di dalam tubuh dikendalikan pada fase absorbsi. Tubuh manusia tidak dapat mengekskresikan Fe. Oleh karena itu, manusia yang sering mendapat transfusi darah, warna kulitnya menjadi hitam karena akumulasi Fe. Sekalipun Fe diperlukan oleh tubuh, dalam dosis besar dapat merusak dinding usus dan dapat menyebabkan kematian. Debu Fe juga dapat diakumulasi di dalam alveoli dan menyebabkan berkurangnya fungsi paruparu.

Syarat konsentrasi Besi (Fe) yang dianjurkan berdasarkan standar baku air bersih Permenkes RI No. 416 /Menkes/ Per/IV/1990 adalah 1.0 mg/l. Apabila kosentrasi besi terlarut dalam air melebihi batas tersebut akan menyebabkan berbagai masalah ,diantaranya : Gangguan teknis Endapan $\mathrm{Fe}(\mathrm{OH})$ bersifat korosif terhadap pipa dan akan mengendap pada saluran pipa, sehingga mengakibatkan pembuntuan dan efek-efek yang dapat merugikan seperti Mengotori bak yang terbuat dari seng. Mengotori wastafel dan kloset.

Keberadaan besi di dalam air dapat menyebabkan air menjadi berwarna, berbau dan berasa. Ada satu orang responden yang menyatakan bahwa air sumur artesisnya berbau amis dan berwarna merah kekeruhan. Kadar besi yang berlebihan selain dapat menyebabkan timbulnya warna merah juga dapat menyebabkan karat pada peralatan yang terbuat dari logam.

Hasil penelitian Nia Yuliani, Nurlela, Novia anggraeni Lestari (2017) tentang Kualitas Air Sumur Bor di Perumahan Bekas Persawahan Gunung Putri Jawa Barat menunjukkan bahwa beberapa sampel air sumur bor memiliki kandungan besi yang berada di atas ambang batas maksimum yang diperbolehkan (lebih dari $1 \mathrm{mg} / \mathrm{L}$ berdasarkan baku mutu air bersih) yaitu untuk S4 yaitu 1,74 mg/L, S12 yaitu $1,998 \mathrm{mg} / \mathrm{L}$, dan $\mathrm{S} 19$ yaitu $1,178 \mathrm{mg} / \mathrm{L}$. Kadar besi yang melebihi ambang batas pada S4, S12, dan S19 kemungkinan disebabkan karena terdapat pengkaratan pada pipa atau keran di dalam pipa/saluran air sehingga mengkontaminasi air yang 
melewatinya. Kedalaman sumur pada S19 yang tidak terlalu dalam dibanding sumur untuk sampel lainnya, yaitu kurang lebih 15 meter berdasarkan keterangan pemilik sumur S19, dan lokasinya yang berdekatan dengan aliran sungai kemungkinan menjadi penyebab adanya kontaminasi unsur besi pada tanah yang merembes pada sumur tersebut.

\section{c. Kualitas air sumur gali}

Kualitas air yang baik tidak selamanya tersedia di alam, bahkan di daerah tertentu air yang tersedia tidak memenuhi syarat kesehatan secara alami, sehingga diperlukan upaya perbaikan secara sederhana maupun modern. Banyak masyarakat yang terpaksa memanfaatkan air yang kurang bagus kualitasnya, dan tentu saja hal ini dapat berakibat kurang baik bagi kesehatan masyarakat. Pada jangka pendek kualitas air yang tidak baik dapat mengakibatkan penyakit diare, muntaber, kolera, tipus dan disentri. Dalam jangka panjang, air yang berkualitas kurang baik dapat mengakibatkan penyakit keropos tulang, korosi gigi, anemia dan kerusakan ginjal, karena terdapat logamlogam berat yang banyak bersifat toksin (racun) dan mengendap pada ginjal. Begitu pula air untuk mandi maupun untuk cucian yang tidak baik dapat berakibat langsung pada kesehatan mata dan kulit.
Pencemaran air terjadi apabila dalam air terdapat berbagai macam zat atau kondisi (panas) yang dapat menurunkan standar kualitas air yang telah ditentukan, sehingga tidak dapat digunakan untuk kebutuhan tertentu. Suatu sumber air dikatakan tercemar tidak hanya karena tercampur dengan bahan pencemar, akan tetapi apabila air tersebut tidak sesuai dengan kebutuhan tertentu. Sebagai contoh suatu sumber air yang mengandung logam berat atau mengandung bakteri penyakit masih dapat digunakan untuk kebutuhan industri atau sebagai pembangkit tenaga listrik, akan tetapi tidak dapat digunakan untuk kebutuhan rumah tangga (keperluan air minum, memasak, mandi dan mencuci).

Berdasarkan penelitian Priska E Pasumah (2017) mengatakan bahwa air bersih di Desa Pesisir hasil tidak memenuhi syarat berdasarkan nilai baku mutu yang ditetapkan dalam Permenkes RI nomor 416 tahun 1990. Hal ini menyebabkan masyarakat harus meningkatkan pengawasan dan pemeliharaan sumber air bersih untuk mempertahankan kualitas air bersih yang ada agar dapat mengurangi resiko masuknya bahan pencemar. Terdapat faktor lain yang menyebabkan kekeruhan pada air sumur yaitu jenis sumur. Untuk sumur gali mudah terkontaminasi melalui rembesan dari tempat pembuangan kotoran 
manusia maupun limbah dari sumur tersebut karena berasal dari lapisan tanah yang relatif dekat dengan permukaan tanah. Faktor lain juga yang mempengaruhi perbedaan nilai kekeruhan air pada pengambilan pertama dan kedua yaitu keadaan cuaca, dimana terjadi hujan pada malam hari hingga pagi hari saat pengambilan dan keadaan cuaca yang panas pada pengambilan sampel kedua.

Hasil penelitian Nia Yuliani, Nurlela, Novia anggraeni Lestari (2017) tentang Indeks Pencemaran menunjukkan bahwa tingkat pencemaran air sumur bor di Perumahan Gunung Putri, Jawa Barat tergolong masih memenuhi baku mutu untuk kualitas air bersih. Seluruh sampel tidak memenuhi standar persyaratan untuk kulaitas air minum dilihat dari baku mutu untuk parameter besi, timbal, warna, bau, dan rasa. sehingga air sumur bor Perumahan tidak layak digunakan untuk minum, namun masih dapat digunakan sebagai air bersih.

\section{KESIMPULAN DAN SARAN}

Kualitas air sumur gali ditinjau dari parameter kimia ( $\mathrm{Cl}$ dan $\mathrm{Fe})$ sebagian dari air sumur gali tidak memenuhi syarat kesehatan. Kualitas air sumur gali berdasarkan parameter kimia Klorida $(\mathrm{Cl})$, 4 dari 12 sumur gali yang diperiksa tidak memenuhi syarat kesehatan. Kualitas air sumur gali berdasarkan parameter kimia besi (Fe), 2 dari 12 sumur gali yang diperiksa tidak memenuhi syarat kesehatan. Diharapkan kepada masyarakat agar kiranya bisa mengontrol dan menjaga kebersihan di sekitar sumur gali agar tidak tercemari. Bagi instansi kesehatan yang terkait agar sebaiknya tetap melakukan penyuluhan tentang masalah lingkungan dan air bersih. Bagi masyarakat yang menggunakan sumur gali untuk memenuhi kebutuhan air air sehari-hari sebaiknya diolah terlebih dahulu. Bagi petugas kesehatan setempat agar kiranya bisa turun memeriksa sumur-sumur gali masyarakat. Untuk peneliti selanjutnya dapat melanjutkan penelitian yang berkaitan tentang air sumur gali tentang cara menurunkan kadar Klorida $(\mathrm{Cl})$ dan Besi (Fe) pada sumur gali.

\section{DAFTAR PUSTAKA}

Aryani, F,D,N. 2017. Kualitas Air Tanah Di Sekitar Lokasi Tempat Pembuangan Akhir untuk Pemenuhan Kebutuhan Air Bersih (Studi Kasus: Tpa Banyuroto Dan Tpa Piyungan). Kualitas Air Tanah. Darmono.2001. LINGKUNGAN HIDUP dan PENCEMARAN Hubungannya dengan Toksikologi Senyawa Logam.Penerbit Universitas Indonesia.Jakarta.

Efendi, H. 2003. Telaah Kualitas Air Bagi Pengelolan Sumber Daya dan Lingkungan Perairan.penerbit kanisius. Yogyakarta.

Hapsari,D. 2015. Kajian Kualitas Air Sumur Gali dan Perilaku Masyarakat di Sekitar Pabrik 
Semen Kelurahan Karangtalun Kecamatan Cilacap Utara Kabupaten Cilacap. Jurnal Sains dan Teknologi Lingkungan. Volume 7 Nomor 1 Januari 2015.

Heluth,O,M.2013. Kualitas Air Sumur Gali Masyarakat Desa Tifu Kecamatan Waeapo Kabupaten Buru Propinsi Maluku. Jurnal MKMI Juni 2013, hal 67-73.

Ihsan,M,F., dkk. 2017. Kajian Kualitas Air Sumur Gali untuk Wilayah Pedalangan yang Mempunyai Ipal Komunal. Jurnal Teknik Lingkungan, Vol. 6, No. 2 (2017).

Notoatmodjo, soekidjo. 2012. Metode Penelitian Kesehatan.Rineka Cipta. Jakarta.

Nugroho,W., S. Purwoto. 2013. Removal Klorida, Tds dan Besi Pada Air Payau Melalui Penukar Ion dan Filtrasi Campuran Zeolit Aktif Dengan Karbon Aktif. Jurnal Teknik WAKTU Volume 11 Nomor 01 - Januari 2013 - ISSN : 1412-1867.

Pasumah, P,E., dkk. 2017. Kualitas Fisika dan Kimia Air Bersih Di Desa Pesisir Minahasa Utara. Studi Kasus Di Desa Marinsow Kecamatan Likupang Timur Fakultas Kesehatan Masyarakat Universitas Sam Ratulangi Manado.

Puji E dkk, 2017. Pedoman Penulisan Skripsi Edisi 15. Buku pedoman Untuk Lingkup Sendiri. Sekolah Tinggi Ilmu Kesehatan Makassar.

Qadafi., M, Amin., B, Edisar., M. 2015. Analisis Kelayakgunaan Air Tanah Dalam Ditinjau dari Aspek Kualitas dan Geologi Lingkungan Di Kota Tembilahan Indragiri Hilir. Jurnal Ilmu Lingkungan 1978-5283.

Sasongko,E,B., dkk. 2014. Kajian Kualitas Air dan Penggunaan Sumur Gali Oleh Masyarakat di Sekitar Sungai Kaliyasa Kabupaten Cilacap. Jurnal Ilmu Lingkungan, Vol 12 (2): 7282, 2014 ISSN : 1829-8907.
Seizarwati,W., H.Rengganis. 2016. Tipologi dan Kualitas SumberSumber Air Di Pulau Yamdena Dan Selaru, Maluku Tenggara Barat. Jurnal Sumber Daya Air Vol.12 No. 1, Mei 2016: $77-88$.

Setyono,A. 2014. Studi Kadar Mangan (Mn) pada Air Sumur Gali Di Desa Karangnunggal Kecamatan Karangnunggal Kabupaten Tasikmalaya. Jurnal Kesehatan Komunitas Indonesia Vol. 10. No. 1 Maret 2014.

Sunarti, R,N. 2015. Uji Kualitas Air Sumur Dengan Menggunakan Metode MPN (Most Probable Numbers). Bioilmi Vol. 1 No. 1 Edisi Agustus 2015.

Susilawati,A, dkk. 2015. Peningkatan Kualitas Air Sumur Gali Berdasarkan Parameter Besi (Fe) dengan Pemanfaatan Kulit Pisang Kepok di Dusun Alekanrung Desa Kanrung Kabupaten Sinjai. AlSihah : Public Health Science Journal 166-174.

Sutrisno, totok. Dkk. 2004. Teknologi Penyediaan Air Bersih. Penerbit rineka cipta.Jakarta.

Tuwu, E,R,. dan Kete, S.C.R. 2017. Analisis Kualitas Air Tanah Berdasarkan Variasi Kedalaman Muka Air di Daerah Aliran Sungai (DAS) Wanggu Kota Kendari, Sulawesi Tenggara. Biowallacea, Vol. 4 (1), Hal : 547-557, April, 2017

Wardhana,W,A. 1994. Dampak pencemaran lingkungan. Penerbit ANDI.Yogyakarta.

Yuliani,N, Nurlela, Lestari,N,A. 2017. Kualitas Air Sumur Bor Di Perumahan Bekas Persawahan Gunung Putri Jawa Barat. SENASPRO $2017 \quad$ Seminar Nasional dan Gelar Produk.

PERMENKES RI NOMOR
492/MENKES/PER/IV/2010
TENTANG N PERSYARATAN
KUALITAS AIR MINUM.




$\begin{array}{llr}\text { PERMENKES } & \text { RI } & \text { NOMOR } \\ \text { 416/MANKES/PER/IX/1990 } \\ \text { TENTANG } & \text { PERSYARATAN } \\ \text { KUALITAS AIR BERSIH. }\end{array}$


Tabel 1. Jumlah Sumur Gali di Kelurahan Mangempang Kec. Barru Kab. Barru

\begin{tabular}{ccc}
\hline Nama lingkungan & Jumlah SGL & Jumlah sampel \\
\hline Mangempang & 7 & 0 \\
Abbatunge & 26 & 3 \\
Garongkong & 10 & 4 \\
Gempunge & 46 & 1 \\
Padongko & 27 & 4 \\
\hline Jumlah & $\mathbf{1 1 6}$ & $\mathbf{1 2}$ \\
\hline
\end{tabular}

Tabel 2. Distribusi Berdasarkan Parameter Kimia Klorida (Cl) Kualitas Air Sumur Gali di Kelurahan Mangempang Kec. Barru Kab. Barru

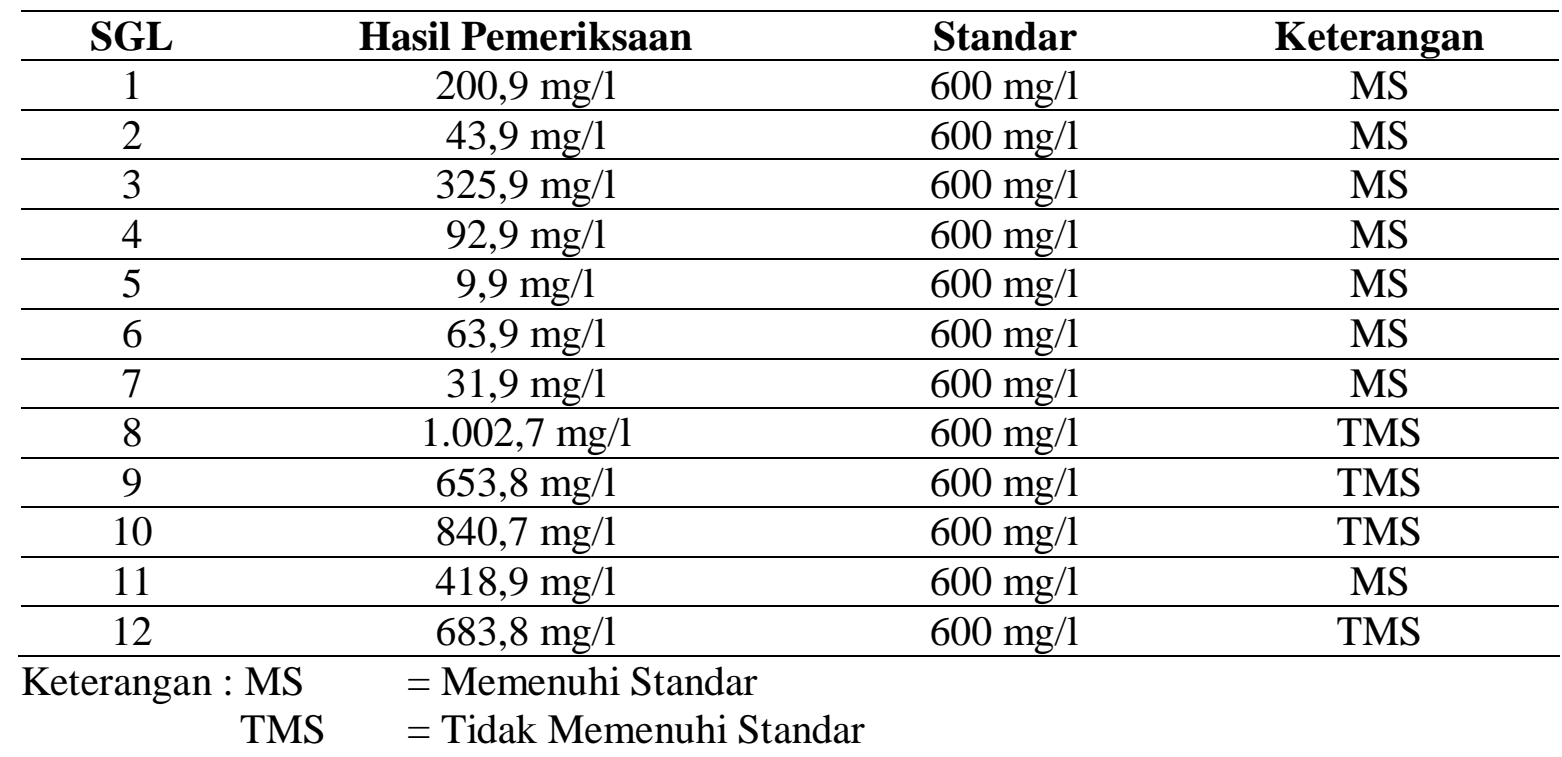

Tabel 3. Distribusi Berdasarkan Parameter Kimia Besi (Fe) Kualitas Air Sumur Gali di Kelurahan Mangempang Kec. Barru Kab. Barru

\begin{tabular}{cccc}
\hline SGL & Hasil Pemeriksaan & Standar & Keterangan \\
\hline 1 & $0,20 \mathrm{mg} / 1$ & $1,0 \mathrm{mg} / 1$ & MS \\
\hline 2 & $0 \mathrm{mg} / 1$ & $1,0 \mathrm{mg} / 1$ & MS \\
\hline 3 & $0,31 \mathrm{mg} / 1$ & $1,0 \mathrm{mg} / 1$ & MS \\
\hline 4 & $0,08 \mathrm{mg} / 1$ & $1,0 \mathrm{mg} / 1$ & MS \\
\hline 5 & $0 \mathrm{mg} / 1$ & $1,0 \mathrm{mg} / 1$ & MS \\
\hline 6 & $0 \mathrm{mg} / 1$ & $1,0 \mathrm{mg} / 1$ & MS \\
\hline 7 & $0,35 \mathrm{mg} / 1$ & $1,0 \mathrm{mg} / 1$ & MS \\
\hline 8 & $1,30 \mathrm{mg} / 1$ & $1,0 \mathrm{mg} / 1$ & MS \\
\hline 9 & $0,23 \mathrm{mg} / 1$ & $1,0 \mathrm{mg} / 1$ & MS \\
\hline 10 & $0,21 \mathrm{mg} / 1$ & $1,0 \mathrm{mg} / 1$ & MS \\
\hline 11 & $1,59 \mathrm{mg} / 1$ & $1,0 \mathrm{mg} / 1$ & MS \\
\hline 12 & $0 \mathrm{mg} / 1$ & $1,0 \mathrm{mg} / 1$ & MS \\
\hline
\end{tabular}

\footnotetext{
Keterangan : MS = Memenuhi Standar

TMS = Tidak Memenuhi Standar
} 